\title{
PANORAMA DA REGULAÇÃO DA INTELIGÊNCIA ARTIFICIAL NO BRASIL: COM ÊNFASE NO PLS N. 5.051/2019
}

\author{
AI REGULATION LANDSCAPE IN BRAZIL: EMPHASIZING THE SENATE BILL \\ $5051 / 2019$
}

\section{PANORAMA DE LA REGULACIÓN DE INTELIGENCIA ARTIFICIAL EN BRASIL: CON ÉNFASIS NEL PROYECTO DE LEY DEL SENADO N. 5.051/2019}

\begin{abstract}
LeONARdo NetTo ParentonI
http://orcid.org/0000-0002-3593-2831 / http:/ / lattes.cnpq.br/3612200644224606 / parentoni@gmail.com UNIVERSIDADE FEDERAL DE MINAS GERAIS - UFMG E INSTITUTO BRASILEIRO DE MERCADO DE CAPITAIS - IBMEC
\end{abstract} BELO HORIZONTE, MG, BRASIL

RÔMULO SOARES VALENTINI

https: / /orcid.org/0000-0003-4340-9917 / http:/ / lattes.cnpq.br/8785190619869300 / rsvalentini@gmail.com FACULDADE PEDRo Leopoldo E Universidade Federal de Minas GeraIs - UFMG BELO HORIZONTE, MG, BRASIL

TÁRIK CÉsAr Oliveira e Alves https://orcid.org/0000-0001-5089-1081/http://lattes.cnpq.br/7756103626245440/tarikcarlves@gmail.com UNIVERSIDADE FEDERAL DE MINAS GERAIS - UFMG BELO HORIZONTE, MG, BRASIL

\begin{abstract}
RESUMO
A inteligência artificial (ou simplesmente IA) é tema presente nos mais diversos ramos científicos e uma das matérias que melhor evidencia a relação entre as novas tecnologias e a necessidade de adequação da sociedade e, consequentemente, também dos sistemas jurídicos. Este estudo é um dos pioneiros no Brasil a tratar do atual panorama regulatório da matéria. Ao longo do texto são mencionadas as principais iniciativas regulatórias sobre IA no país, com ênfase e aprofundamento na análise de alguns dispositivos do Projeto de Lei do Senado n. 5.051/2019, o primeiro que se propôs a enfrentar o tema. O problema identificado é o descompasso entre esse projeto de lei e o atual funcionamento prático da tecnologia, bem como as deficiências técnicas constantes do projeto. O método utilizado foi o descritivo, com apoio na literatura jurídica de referência, nacional e estrangeira, acrescida da opinião dos autores, todos pesquisadores da área. Ao final, conclui-se que o PLS n. 5.051/2019 tem alguns méritos, mas peca por conter erros técnico-jurídicos e por estar em dissintonia com o modo como a IA funciona na prática.
\end{abstract}

Palavras-chave: Inteligência Artificial; Projetos de Lei; Regulação.

\section{ABSTRACT}

Artificial intelligence (or just Al) is a subject presented in the most varied scientific fields and one of the matters that best highlights the relationship between new technologies and the need for adaptations in society and the legal systems. This paper is one of the pioneers in Brazil to address the current regulatory landscape of that matter. The text mentions some of the main Al regulatory initiatives currently in place in the country, emphasizing and digging deeper into some provisions of the Senate Bill 5051/2019, the first one aimed at that subject. The research problem is the mismatch between the Senate Bill and how the technology currently works in the field, as much as the technical shortcomings of the bill. The research method was descriptive and based on the legal literature, both national and international, plus 
LEONARDO NETTOO PARENTONI RÔMULO SOARES VALENTINI TÁRIK CÉSAR OLIVEIRA E ALVES

the author's opinions, all of whom are researchers in this field. In the end, the conclusion is that the Senate Bill $5051 / 2019$ has some merits but contain technical errors and mismatches the way Al really works.

Keywords: Artificial Intelligence; Bills; Regulation.

\section{RESUMEN}

La inteligencia artificial (o simplemente IA) é un tema presente en los diversos campos científicos y una de las materias que mejor demuestra la relación entre nuevas tecnologías y la necesidad de adecuación de la sociedad e de los sistemas jurídicos. Este estudio es uno de los primeros en Brasil a tratar del panorama regulatorio en la materia. A lo largo del texto son mencionadas las principales iniciativas regulatorias sobre IA nel país, con énfasis en el análisis de algunos dispositivos del Proyecto de Ley del Senado n. 5.051/2019. El problema de la investigación es el desajuste entre esto proyecto y el actual funcionamiento práctico de la tecnología, así como las deficiencias técnicas del proyecto. El método fue descriptivo, basado en la literatura jurídica nacional y extranjera, sumada a la opinión de los auctores. Al fin, se concluye que el Proyecto de Ley n. 5.051/2019 tiene sus méritos, pero contiene errores técnico-jurídicos y está en disonancia con el modo como la IA funciona.

Palabras clave: Inteligencia Artificial; Proyectos de Ley; Regulación.

\section{SUMÁRIO}

INTRODUÇÃO; 1 PANORAMA DA ATUAL REGULAÇÃO DE IA NO BRASIL; 2 ANÁLISE CRÍTICA DO PROJETO DE LEI DO SENADO N. 5.051/2019; 2.1 Escopo da Lei; 2.2 Princípios; 2.3 Trabalho e Desenvolvimento Econômico; 2.4 Supervisão Humana e Responsabilidade Civil; 2.5 Diretrizes para o Poder Público; 2.6 Período de Adaptação; CONCLUSÃO; REFERÊNCIAS.

\section{INTRODUÇÃO}

A inteligência artificial (ou simplesmente IA) é tema presente nos mais diversos ramos científicos e uma das matérias que melhor evidencia a relação entre as novas tecnologias e a necessidade de adequação da sociedade e, consequentemente, também dos sistemas jurídicos. Os incentivos à pesquisa e desenvolvimento nessa área são cada vez maiores, com algumas empresas e países investindo elevadas somas para alcançar protagonismo, com destaque para a disputa entre Estados Unidos da América ${ }^{1}$ e China²

\footnotetext{
1 Segundo dados de pesquisa feita pela consultoria Deloitte e publicada em 2018, os Estados Unidos da América haviam investido mais de 05 bilhões de dólares em IA, em 2017. Estudo disponível em: https://www2.deloitte.com/us/en/insights/focus/cognitive-technologies/ai-investment-by-country.html. Acesso em: 22 mar. 2020.

${ }^{2}$ Ainda que as estatísticas na China não sejam tão transparentes nem fáceis de acessar quanto nos EUA, há estudos científicos estimando investimentos em IA de até 10 bulhões de dólares em 2018. Por exemplo: ACHARYA, Ashwin; ARNOLD, Zachary. Chinese Public Al R\&D Spending: Provisional Findings. Center for Security and Emerging Technology - CSET Research. p. 01-31. Dec. 2019. p. 14.
} 
PANORAMA DA REGULAÇÃO DA INTELIGÊNCIA ARTIFICIAL NO BRASIL: COM ÊNFASE NO PLS N. 5.051/2019

LEONARDO NETTOO PARENTONI RÔMULO SOARES VALENTINI TÁRIK CÉSAR OLIVEIRA E ALVES

As primeiras pesquisas científicas nessa área datam de 1943, mais especificamente os trabalhos de Warren McCulloch e Walter Pitts nos Estados Unidos da América ${ }^{3}$. Todavia, a criação do termo “inteligência artificial” deu-se apenas em 1956, quando foi sugerido por John McCarthy durante uma de duas apresentações no Dartmouth College, em Hanover/New Hampshire ${ }^{4}$. A partir de então foram publicados dezenas de estudos científicos sobre o tema ${ }^{5}$. Apesar disso, os investimentos na área e a aplicação prática dessa tecnologia continuaram extremamente restritos nas décadas seguintes, motivo pelo qual elas foram apelidadas de "inverno da IA" (AI winter), numa alusão ao fato de que em alguns países a vegetação não cresce ou cresce mais lentamente durante o inverno ${ }^{6}$. 0 que se considerava como IA naquela época nem de longe se assemelha aos atuais sistemas de inteligência artificial. Algo que não surpreende, pois há uma tendência de se associar IA apenas às mais recentes inovações de cada época, em especial àquelas que ainda não se disseminaram ${ }^{7}$. Por outro lado, aplicações que se tornaram rotineiras deixam de ser lembradas como IA. Por exemplo, os primeiros softwares que jogavam xadrez já foram considerados o auge dessa tecnologia em décadas passadas. Hoje, porém, o que se associa a ela são as novas fronteiras prestes a serem quebradas, como os carros autônomos.

A superação do $A l$ winter ocorreu a partir dos anos 2.000 , em virtude da conjunção de alguns fatores, que podem ser assim resumidos ${ }^{8}$ : (i) aumento exponencial na quantidade de dados armazenados online (transição de uma sociedade baseada no papel para a sociedade digital); (ii) aumento na capacidade de processamento dos dispositivos eletrônicos (o que ampliou também a velocidade de processamento); (iii) redução do custo de transmissão e armazenamento de dados (conexões de internet com maior velocidade e largura de banda, além de maior capacidade e

\footnotetext{
${ }^{3}$ Conforme pormenorizadamente descrito em: RUSSELL, Stuart J.; NORVIG, Peter. Artificial Intelligence: A Modern Approach. 3. ed. New Jersey: Prentice-Hall, 2010. p. 16.

${ }^{4}$ KAPLAN, Jerry. Artificial Intelligence: What everyone needs to know. Oxford: Oxford University Press, 2016. p. 13.

${ }_{5}$ Para um compilado desses vários estudos, consulte-se: NILSSON, Nils J. The Quest for Artificial Intelligence: A History of Ideas and Achievements. Cambridge: Cambridge University Press, 2010.

${ }^{6}$ RUSSELL, Stuart J.; NORVIG, Peter. Artificial Intelligence: A Modern Approach. 3. ed. New Jersey: Prentice-Hall, 2010. p. 16. p. 24.

${ }^{7}$ KAPLAN, Jerry. Artificial Intelligence: What everyone needs to know. Oxford: Oxford University Press, 2016. p. 152. "Technologies that are sometimes greeted with concern and alarm by those living during their introduction are often accepted as commonplace and unremarkable by future generations. Examples include the intrusion of television into our homes, in vitro fertilization and, more recently, the tyranny inflicted by social media on our personal relationships with friends and family."

${ }^{8}$ Com apoio na literatura especializada. Por exemplo: MAYER-SCHÖNBERGER, Viktor; CUKIER, Kenneth. Big Data. 2. ed. Boston/New York: Eamon Dolan/Houghton Mifflin Harcourt, 2014. p. 09; CALO, Ryan. Artificial Intelligence Policy: A Primer and Roadmap. University of Washington Research Paper. p. 01-28. August 2017. p. 04.
} 
PANORAMA DA REGULAÇÃO DA INTELIGÊNCIA ARTIFICIAL NO BRASIL: COM ÊNFASE NO PLS N. 5.051/2019

LEONARDO NETTOO PARENTONI RÔMULO SOARES VALENTINI TÁRIK CÉSAR OLIVEIRA E ALVES

menor custo dos hard drives e de outros dispositivos de armazenamento de dados); e (iv) conexão de dispositivos eletrônicos em tempo real (por exemplo, no contexto de internet das coisas - loT ${ }^{9}$ ). A combinação desses ingredientes proporcionou o desenvolvimento rápido da tecnologia, a ponto de em 2016 o Governo dos Estados Unidos da América sugerir maiores investimentos na área, a fim de "deixar mil flores desabrocharem" (letting a thousand flowers bloom) ${ }^{10}$.

É fato que o Brasil - assim como vários outros países em desenvolvimento - não participou ativamente dessa “corrida" por aplicações baseadas em IA. Contudo, recentemente e num curto espaço de tempo o país passou a discutir simultaneamente várias iniciativas na área, tanto no âmbito legislativo quanto no executivo. O propósito deste estudo é trazer um panorama do atual cenário regulatório da matéria no Brasil, bem como aprofundar a análise do Projeto de Lei do Senado n. 5.051/2019, que por ser o pioneiro a tratar do tema quer porque as considerações feitas a respeito dele são de ordem geral e podem ser aplicadas a qualquer outra iniciativa regulatória. Para isso será utilizado o método descritivo, com apoio na literatura jurídica de referência, tanto nacional quanto estrangeira, acrescida da opinião fundamentada dos autores, todos pesquisadores da área. Os dois principais problemas evidenciados ao longo da pesquisa foram o fato de que o referido projeto de lei está em profundo descompasso com o modo como a IA funciona na prática, além de conter imprecisões e equívocos técnico-jurídicos, os quais serão detalhados neste estudo.

0 artigo será desenvolvido ao longo de dois tópicos principais: 1) Panorama da atual regulação de IA no Brasil; e 2) Análise crítica do Projeto de Lei do Senado n. 5.051/2019, seguidos de breve conclusão e referências.

\footnotetext{
${ }^{9}$ MAGRANI, Eduardo; OLIVEIRA, Renan Medeiros de. A internet das coisas e a Lei Geral de Proteção de Dados: reflexões sobre os desafios do consentimento e do direito à explicação. Revista do Advogado. São Paulo: AASP, Ano XXXIX, n. 144, p. 80-89, nov. 2019. p. 80-81. "Existem fortes divergências em relação ao conceito de internet das coisas (em inglês, o internet of things (loT)), e não há um consenso sobre um que seja capaz de abarcar a complexidade sociotécnica de tal fenômeno. De maneira geral, a loT refere-se a um ambiente de objetos físicos interconectados com a internet e que cria um ecossistema de computação onipresente com o objetivo de facilitar e trazer soluções a desafios do dia a dia que afligem as pessoas. Algo que todas as definições de loT têm em comum é que elas se concentram em como computadores, sensores e objetos interagem uns com os outros e processam as informações/dados em um contexto de hiperconectividade."

${ }^{10}$ ESTADOS UNIDOS DA AMÉRICA. Relatório do Comitê de Tecnologia do Conselho Nacional de Ciência e Tecnologia para o Escritório Executivo do Presidente. Preparing for the Future of Artificial Intelligence, October $12^{\text {th }} 2016.2016 .2$ Disponível https://www.whitehouse.gov/sites/default/files/whitehouse_files/microsites/ostp/NSTC/preparing_for_t he_future_of_ai.pdf. Acesso em: 24 abr. 2018.
} 


\section{PANORAMA DA ATUAL REGULAÇÃO DE IA NO BRASIL}

Até agosto de 2019, o Brasil não contava com propostas significativas de regulação da inteligência artificial. Esse cenário modificou-se de maneira abrupta e até surpreendente nos meses seguintes.

Em setembro e outubro de 2019, dois projetos de lei focados no tema foram sucessivamente apresentados ao Senado Federal, ambos pelo Senador Styvenson Valentim. São os projetos de n. 5.051/2019 e 5.691/2019 ${ }^{12}$. Em resposta, o Poder Executivo, por meio da Secretaria de Telecomunicações (integrante do Ministério da Ciência, Tecnologia, Inovações e Comunicações - MCTIC) iniciou consulta pública denominada Estratégia Brasileira de Inteligência Artificial $^{13}$. Ainda que o desenvolvimento de uma estratégia nacional sobre IA já houvesse sido mencionado em iniciativa anterior do próprio MCTIC, em 2018, denominada Estratégia Brasileira para a Transformação Digital - E-Digital (Decreto n. 9.313/2018), há rumores de que a consulta pública foi uma resposta direta aos projetos de lei do Senado, no intuito de que o Poder Executivo retomasse o protagonismo na regulação da matéria. Por isso era esperado que após o término da consulta, ocorrido em março de 2020, as sugestões nela recebidas fossem analisadas e inseridas em projeto de lei sobre o tema, de iniciativa do próprio Executivo. Ocorre que a participação na consulta pública foi muito baixa, praticamente se restringindo a estudiosos da área e alguns poucos centros de pesquisa. Nenhuma das grandes empresas do setor se manifestou. Consequentemente, os resultados não podem ser considerados amostra satisfatória do que os vários stakeholders ${ }^{14}$ pensam sobre o tema. Consequentemente, sua utilidade foi reduzida de forma que tende a ser

11 BRASIL. Senado da República. Projeto de Lei 5.051/2019. 2019. Disponível em: https://www25.senado.leg.br/web/atividade/materias/-/materia/138790. Acesso em: 09 fev. 2020. 12 BRASIL. Senado da República. Projeto de Lei 5.691/2019. 2019. Disponível em: https://www25.senado.leg.br/web/atividade/materias/-/materia/139586. Acesso em: 09 fev. 2020. 13 BRASIL. Ministério da Ciência, Tecnologia, Inovações e Comunicações - MCTIC. Consulta Pública: Estratégia Brasileira de Inteligência Artificial. 2019. Disponível em: http://participa.br/profile/estrategia-brasileira-de-inteligencia-artificial. Acesso em: 09 fev. 2020.

${ }^{14}$ SCHWAB, Klaus. A Quarta Revolução Industrial. Tradução: Daniel Moreira Miranda. São Paulo: Edipro, 2016. p. 12. "Se, por um lado, a profunda incerteza que rodeia o desenvolvimento e a adoção de tecnologias emergentes significa que ainda não conhecemos os desdobramentos das transformações geradas por essa revolução industrial, por outro, a complexidade e a interconexão entre os setores implicam que todos os stakeholders da sociedade global - governos, empresas, universidades e sociedade civil - devem trabalhar juntos para melhor entender as tendências emergentes." 


\section{DIREITO}

PANORAMA DA REGULAÇÃO DA INTELIGÊNCIA ARTIFICIAL NO BRASIL: COM ÊNFASE NO PLS N. 5.051/2019

LEONARDO NETTOO PARENTONI RÔMULO SOARES VALENTINI TÁRIK CÉSAR OLIVEIRA E ALVES

lembrada mais como um fato histórico no processo regulatório do tema no Brasil do que propriamente como efetiva contribuição.

Em fevereiro de 2020, surgiram duas outras iniciativas dignas de nota e que tendem a apresentar impacto prático muito maior do que a consulta pública mencionada anteriormente. Primeiro, o MCTIC abriu chamada de propostas para financiar a instalação no país de até 08 Centros de Pesquisas Aplicadas em Inteligência Artificial ${ }^{15}$. Cada um deles deveria receber anualmente do governo 1 milhão de reais, além de outros 1 milhão provenientes de parceiros privados, durante pelo menos 05 anos. Cada centro de pesquisa deveria ser especializado em um setor, definido pelo Poder Executivo, a fim de evitar sobreposições e otimizar o emprego dos recursos. Para os 4 primeiros centros, esses setores seriam: (i) saúde; (ii) agricultura; (iii) indústria; e (iv) cidades inteligentes. Dos outros 4 centros, a serem instalados em momento posterior, um deles seria especializado em segurança cibernética e deveria trabalhar próximo ao Exército Brasileiro, enquanto o outro teria como foco aplicações de IA para o setor público.

A segunda iniciativa digna de nota foi o Projeto de Lei da Câmara n. 21/2020 ${ }^{16}$, proposto pelo Deputado Eduardo Bismarck. Apesar de ter alguns pontos de contato com os projetos do Senado, a iniciativa do Deputado Eduardo Bismarck é mais completa e tecnicamente precisa, ainda que também necessite de aprimoramentos. Este projeto de lei atraiu o protagonismo do tema na Câmara dos Deputados e vem sendo tratado como o principal projeto sobre IA naquela casa legislativa, tanto que outros projetos estão sendo apensadas a ele, para terem tramitação legislativa conjunta, como o PL n. 240/202017 de autoria do Deputado Léo Moraes.

Ainda que este estudo se aprofunde na análise técnica do PLS n. 5.051/2019, por ser o primeiro do Brasil nessa matéria, as considerações feitas a seguir são de natureza geral/estrutural, as quais podem e devem ser consideradas em qualquer iniciativa regulatória sobre inteligência artificial, de modo que permanecem válidas e úteis, aplicando-se também aos demais projetos de lei em tramitação no Congresso Nacional.

\footnotetext{
15 BRASIL. Ministério da Ciência, Tecnologia, Inovações e Comunicações - MCTIC. Chamada de Propostas para a Criação de Centros de Pesquisas Aplicadas em Inteligência Artificial. 2020. Disponível em: http://www.mctic.gov.br/mctic/opencms/tecnologia/inteligencia_artificial/ChamadaPropostasCriacaoCe ntrosPesquisasAplicadasemInteligencia_Artificial_0.html. Acesso em: $23 \mathrm{fev} .2020$.

16 BRASIL. Câmara dos Deputados. Projeto de Lei 21/2020. 2020. Disponível em: https: //www.camara.leg.br/proposicoesWeb/fichadetramitacao?idProposicao=2236340. Acesso em: 15 mar. 2020.

17 BRASIL. Câmara dos Deputados. Projeto de Lei 240/2020. 2020. Disponível em: https: / / www.camara.leg.br/proposicoesWeb/fichadetramitacao?idProposicao=2236943. Acesso em: 20 jul. 2020.
} 
LEONARDO NETTO PARENTONI RÔMULO SOARES VALENTINI TÁRIK CÉSAR OLIVEIRA E ALVES

Em síntese, portanto, o panorama regulatório da inteligência artificial no Brasil, em março de 2020, contava com 04 marcos principais: (i) os Projetos de Lei do Senado n. 5.051/2019 e 5.691/2019, ambos de autoria do Senador Styvenson Valentim; (ii) a consulta pública do MCTIC denominada Estratégia Brasileira de Inteligência Artificial; (iii) a chamada de propostas também do MCTIC para financiar a instalação de até 08 Centros de Pesquisas Aplicadas em Inteligência Artificial; e (iv) o Projeto de Lei da Câmara dos Deputados n. 21/2020.

Tudo levava a crer que 2020 seria o ano de ouro para a regulação da IA no Brasil, com bastante otimismo da comunidade científica em relação aos avanços na área e à aprovação - com aprimoramentos - de ao menos um desses projetos de lei, além da instalação dos primeiros centros de pesquisa aplicada do setor, idealizados para alçar o país a outro patamar.

Entretanto, o súbito desenrolar da epidemia do novo coronavírus (COVID-19) tornou-se, com muita razão, o centro das atenções mundiais, quer pela dimensão global do fenômeno, quer pelos graves efeitos socioeconômicos que ele já causou e deve continuar causando. Isto certamente irá alterar as prioridades do Brasil para os próximos meses. Neste novo contexto, torna-se impossível saber quando e em que medida a regulação de IA voltará a ser prioridade. Afinal, por mais que o tema seja relevante, a saúde e a sobrevivência das pessoas são valores muito maiores e que demandam foco imediato. Todavia, quando os holofotes se voltarem novamente à regulação de IA, o que certamente acontecerá em algum momento futuro, esperase que este estudo traga contribuições relevantes, até por ter sido um dos pioneiros do Brasil a enfrentar o tema.

\section{ANÁLISE CRÍTICA DO PROJETO DE LEI DO SENADO N. 5.051/2019}

Optou-se por analisar em detalhes o Projeto de Lei do Senado n. 5.051/2019 porque ele foi o primeiro do país a propor a regulação de inteligência artificial. Não obstante, as considerações desenvolvidas neste tópico não têm sua utilidade restrita exclusivamente a este projeto. Ao contrário, evidenciam aspectos gerais e estruturantes, os quais devem ser observados em qualquer iniciativa regulatória sobre o tema, de modo que permanecem úteis e relevantes ainda que, no futuro, o foco eventualmente seja direcionado a outro projeto de lei. Como método optou-se por transcrever literalmente cada um dos artigos do PLS n. 5.051/2019, em subitens deste tópico, procedendo-se em seguida a sua análise científica. 


\section{UDIREITO}

PANORAMA DA REGULAÇÃO DA INTELIGÊNCIA ARTIFICIAL NO BRASIL: COM ÊNFASE NO PLS N. 5.051/2019

LEONARDO NETTO PARENTONI RÔMULO SOARES VALENTINI TÁRIK CÉSAR OLIVEIRA E ALVES

\subsection{Escopo da Lei}

Art. $1^{\circ}$ Esta Lei estabelece os princípios para o uso da Inteligência Artificial no Brasil.

O primeiro artigo do projeto se presta a definir o objetivo da lei: regular a utilização de inteligência artificial no Brasil, de forma principiológica.

A proposta de enunciar princípios e conceitos jurídicos indeterminados ${ }^{18}$, ao invés de regras "fechadas", é técnica elogiável sobretudo quando o objeto a ser regulado envolve novas tecnologias, em constante e rápida mutação, com elevado potencial econômico ${ }^{19}$ mas também acompanhadas de sérios riscos, como é o caso da $\mathrm{IA}^{20}$. Nesse aspecto, portanto, andou bem o projeto de lei. Essa mesma técnica vem sendo utilizada em iniciativas regulatória de outros países, como no Self Drive Act $2017^{21}$, dos Estados Unidos da América.

Ocorre que boas intenções não bastam para regular um tema tão complexo. A abordagem precisa ser técnica e conectada com o modo como a tecnologia funciona na prática. Sob estes dois prismas, no entanto, o projeto de lei carece de aprimoramentos.

Primeiro, pelo fato de que não delimitou com a devida precisão técnica o que se deve considerar como "inteligência artificial" para fins de incidência da lei. Até porque não existe uma seção de definições no projeto, tal como recomendado para leis que tratam de temas muito técnicos e específicos, à semelhança do que foi feito no Brasil, por exemplo, no artigo $5^{\circ}$ da Lei Geral de Proteção de Dados Pessoais (LGPD - Lei n. 13.709/2018). No assunto em exame, esse tipo

\footnotetext{
18 THEODORO JÚNIOR, Humberto. O Contrato e sua Função Social. 2. ed. Rio de Janeiro: Forense, 2004. p. 115-116. "Não se sentindo o legislador atual capacitado a normatizar detalhadamente e com plena eficácia os direitos conquistados pela sociedade contemporânea, viu-se obrigado a lançar mão de outra técnica legislativa, cuja especificidade está no prestígio dos critérios hermenêuticos. Com esse propósito, incrementaram-se as normas descritivas ou narrativas, cuja tônica não é preceptiva, mas axiológica. Por meio delas, definem-se modelos de conduta à luz de princípios que irão orientar o intérprete, tanto nas situações já tipificadas como nas atípicas (i.e., as não previstas no ordenamento)."

${ }^{19}$ Sobre o potencial econômico da inteligência artificial, consulte-se o seguinte relatório do MIT em parceria com o Boston Consulting Group, do ano de 2019. Disponível em: https://sloanreview.mit.edu/projects/winning-withai/?utm_medium=email\&utm_source=newsletter\&utm_campaign=airpt2019. Acesso em: 17 out. 2019.

${ }^{20}$ CATH, Corinne; et alii. Artificial Intelligence and the 'Good Society': the US, EU, and UK approach. Science and Engineering Ethics. New York: Springer. v. 23, n. 02, p. 01-24, Jan. 2017. p. 21. "Al can easily become the elephant in the crystal room, if we do not pay attention to its development and application."

${ }^{21}$ ESTADOS UNIDOS DA AMÉRICA. Congresso Nacional. House Resolution 3388 de 09 de julho de 2017. 2017. Disponível em: https://www.congress.gov/bill/115th-congress/house-bill/3388. Acesso em: 07 out. 2019.
} 
PANORAMA DA REGULAÇÃO DA INTELIGÊNCIA ARTIFICIAL NO BRASIL: COM ÊNFASE NO PLS N. 5.051/2019

LEONARDO NETTOO PARENTONI RÔMULO SOARES VALENTINI TÁRIK CÉSAR OLIVEIRA E ALVES

de definição é indispensável, uma vez que IA é um termo polissêmico ${ }^{22}$ e que se refere a uma tecnologia multipropósito, passível de ser utilizada em várias áreas (como robótica, visão computacional, reconhecimento de fala, automação, etc.), para os mais distintos objetivos e valendo-se de técnicas variadas, como aprendizado de máquina (machine learning) supervisionado ou não supervisionado e as redes neurais (neural networks). A maior efetividade do projeto de lei depende, então, de se definir com clareza qual é o objeto a ser regulado. Nessa tarefa, a observação de iniciativas estrangeiras pode ser um bom ponto de partida. Internacionalmente existem tanto definições sucintas quanto extensas de inteligência artificial.

Exemplo de definição sucinta é que consta do Algorithmic Accountability Act dos Estados Unidos da América, o qual conceitua IA como sendo: “técnicas de aprendizado de máquina e quaisquer outras técnicas de processamento de dados que tomem decisões automatizadas ou que facilitem a tomada de decisão humana capaz de gerar efeitos sobre consumidores"23. Em sentido contrário, há definição extensa no primeiro artigo da seção de definições do FUTURE of Artificial Intelligence Act, de 2017, dos Estados Unidos da América:

I - Sistema artificial que execute tarefas em circunstâncias variadas e imprevisíveis, sem supervisão humana significativa, ou que possa aprender com a experiência e melhorar o desempenho. Que tais sistemas podem ser desenvolvidos em software de computador, hardware físico ou outros contextos ainda não contemplados. Eles podem resolver tarefas que exijam percepção, cognição, planejamento, aprendizado, comunicação ou ação física semelhante à humana. Em geral, quanto mais humano for o sistema no contexto de suas tarefas, mais se pode dizer que usa inteligência artificial;

II - Sistemas que pensam como seres humanos, como arquiteturas cognitivas e redes neurais;

III - Sistemas que agem como seres humanos, como sistemas que podem passar no teste de Turing ou outro teste comparável por meio do processo de linguagem natural, representação do conhecimento, raciocínio automatizado e aprendizado;

\footnotetext{
22 KAPLAN, Jerry. Artificial Intelligence: What everyone needs to know. Oxford: Oxford University Press, 2016. p. 01. "[What is artificial intelligence?]. That's an easy question to ask and a hard one to answer - for two reasons. First, there's little agreement about what intelligence is. Second, there's scant reason to believe that machine intelligence bears much relationship to human intelligence, at least so far.

There are many proposed definitions of artificial intelligence (Al), each with its own slant, but most are roughly aligned around the concept of creating computer programs or machines capable of behavior we would regard as intelligent if exhibited by humans."

CALO, Ryan. Artificial Intelligence Policy: A Primer and Roadmap. University of Washington Research Paper. p. 01-28. August 2017. p. 04. "There is no straightforward, consensus definition of artificial intelligence. Al is best understood as a set of techniques aimed at approximating some aspect of human or animal cognition using machines."

23 ESTADOS UNIDOS DA AMÉRICA. Congresso. House Resolution 2231 de 10 de abril de 2019. Disponível em: https://www.congress.gov/bill/116th-congress/house-bill/2231?s=1\&tr=91 >. Acesso em: 07 out. 2019.
} 
PANORAMA DA REGULAÇÃO DA INTELIGÊNCIA ARTIFICIAL NO BRASIL: COM ÊNFASE NO PLS N. 5.051/2019

LEONARDO NETTO PARENTONI RÔMULO SOARES VALENTINI TÁRIK CÉSAR OLIVEIRA E ALVES

IV - Um conjunto de técnicas, incluindo aprendizado de máquina, que buscam aproximar alguma tarefa cognitiva;

$\mathrm{V}$ - Sistemas que agem racionalmente, como agentes de software inteligentes e robôs incorporados que alcançam objetivos por meio de percepção, planejamento, raciocínio, aprendizado, comunicação, tomada de decisão e ação. ${ }^{24}$

Cabe ao legislador brasileiro, portanto, decidir que tipo de definição pretende adotar se sucinta e principiológica ou mais extensa e descritiva - inserindo-a claramente na lei, para maior previsibilidade e segurança de todos os sujeitos envolvidos.

Além da própria definição de inteligência artificial, há outros termos técnicos que também devem ser considerados. Por exemplo, a diferença entre IA forte (wide) e fraca (narrow). Esta última é aquela que se limita a desenvolver uma ou mais atividades específicas para as quais foi programada, como uma máquina industrial especializada na produção de determinado componente, ou um programa de computador para jogar determinado game. Diversamente, IA forte é aquela capaz de desenvolver variadas atividades e, inclusive, "aprender" a fazer coisas novas ao longo do tempo. Quanto mais especializada for a aplicação de IA, em tese mais eficiente ela será, suplantando facilmente a capacidade de um ser humano na execução da mesma tarefa. Por outro lado, no estágio atual de desenvolvimento dessa tecnologia, ainda não existe uma IA forte o suficiente para se adequar a praticamente qualquer tarefa e ter "consciência" do que faz, tal como o ser humano. Se algum dia esse estágio de desenvolvimento tecnológico for alcançado, a literatura especializada sugere chamá-lo de singularidade $e^{25}$ ou superinteligência ${ }^{26}$.

Do ponto de vista estrutural, há ainda outra decisão relevante que precisa ser tomada: haverá uma lei geral de regulação da IA, aplicada a todos os setores de mercado, por mais diversos que sejam - como saúde, educação, entretenimento, comércio, etc. - ou seria melhor editar leis específicas para cada setor. Terceira possibilidade seria, ainda, conciliar a lei geral de base principiológica (definindo o mínimo que se espera da IA em qualquer setor), com leis específicas que atentem às necessidades próprias de cada segmento. Sendo que nesta terceira hipótese, todas as leis setoriais deveriam observar os princípios contidos na lei geral.

24 Estados Unidos da América. Congresso. House Resolution. 2486 de 05 de fevereiro de 2019. Disponível em: https://www.congress.gov/bill/116th-congress/house-bill/2486/text. Acesso em: 07 out. 2019.

25 KURZWEIL, Ray. The Singularity Is Near: When Humans Transcend Biology. New York: Penguin Group, 2005. p. 24. "What, then, is the Singularity? It's a future period during which the pace of technological change will be so rapid, its impact so deep, that human life will be irreversibly transformed. Although neither utopian nor dystopian, this epoch will transform the concepts that we rely on to give meaning to our lives, from our business models to the cycle of human life, including death itself. Understanding the Singularity will alter our perspective on the significance of our past and the ramifications for our future." ${ }^{26}$ BOSTROM, Nick. Superintelligence: Paths, Dangers, Streategies. Oxford: Oxford University Press, 2014. 
A precisa delimitação técnica do escopo da lei e a definição da estratégia legislativa para tratar do tema são, portanto, dois pontos estruturantes, preliminares e indispensáveis.

\title{
2.2 Princípios
}

\begin{abstract}
Art. $2^{\circ} \mathrm{A}$ disciplina do uso da Inteligência Artificial no Brasil tem como fundamento o reconhecimento de que se trata de tecnologia desenvolvida para servir as pessoas com a finalidade de melhorar o bem-estar humano em geral, bem como: I - o respeito à dignidade humana, à liberdade, à democracia e à igualdade; II - o respeito aos direitos humanos, à pluralidade e à diversidade;

III - a garantia da proteção da privacidade e dos dados pessoais; IV - a transparência, a confiabilidade e a possibilidade de auditoria dos sistemas; $\mathrm{V}$ - a supervisão humana.
\end{abstract}

O artigo em exame elenca os princípios que deveriam guiar a utilização da IA no Brasil. Sobre as vantagens de se utilizar a técnica principiológica nessa matéria já se discorreu brevemente no tópico anterior. Cumpre, agora, analisar os princípios sugeridos pelo projeto.

A começar pelo caput do artigo, que consagra a preponderância do ser humano, também conhecida como human-centered Al. Ou seja, interesses comerciais e de outras naturezas são secundários no trato dessa matéria. Algo que se conecta diretamente com o princípio da dignidade da pessoa humana, fundamento da República previsto no art. $1^{\circ}$, III da Constituição Federal. 0 respeito aos direitos humanos, à pluralidade e à diversidade, previsto no inciso II do projeto de lei, também é ponto de consenso entre os estudiosos do tema ${ }^{27}$.

Já o inciso III do projeto, que trata da proteção à privacidade e aos dados pessoais, merece algumas considerações. Em primeiro lugar, já existe lei publicada sobre esse tema no país, ainda que não tenha entrado em vigor. Trata-se da LGPD, citada anteriormente. Nesse caso, seria mais técnico que qualquer proposta regulatória mencionasse privacidade e proteção de dados pessoais "nos termos da lei”, para destacar a necessária conexão com a LGPD. E mais do que isso, é preciso assegurar que haja efetivo diálogo e compatibilidade entre qualquer regulação de IA e a LGPD, evitando-se previsões contraditórias. Aspecto que não foi observado no caso pois, como se demonstrará em tópico posterior, o projeto de lei do Senado conflita com o art. 20 da LGPD, que trata do direito à explicação e à revisão de decisões exclusivamente automatizadas ${ }^{28}$.

\footnotetext{
27 Vide, por exemplo: CATH, Corinne; et al. Artificial Intelligence and the 'Good Society': the US, EU, and UK approach. Science and Engineering Ethics. New York: Springer. v. 23, n. 02, p. 01-24, Jan. 2017.

28 Existe acalorado debate na sobre esse tema na literatura especializada, com posicionamentos antagônicos. Por exemplo: EDWARDS, Lilian; VEALE, Michael. Slave to the Algorithm? Why a 'Right to an
} 
PANORAMA DA REGULAÇÃO DA INTELIGÊNCIA ARTIFICIAL NO BRASIL: COM ÊNFASE NO PLS N. 5.051/2019

LEONARDO NETTO PARENTONI RÔMULO SOARES VALENTINI TÁRIK CÉSAR OLIVEIRA E ALVES

0 inciso IV destaca os princípios da transparência, confiabilidade e possibilidade de auditoria dos sistemas (accountability). Ainda que esses sejam também objetivos inegavelmente desejáveis, é preciso ter consciência de que, na prática, existe um trade off entre a eficiência do sistema e a possibilidade de compreender como ele funciona de fato (ou seja, quais foram os critérios considerados para tomar determinada decisão e o "peso" atribuído a cada um). Quanto maior a eficiência, menor tende a ser a transparência do sistema, aspecto que a literatura especializada, em tom de crítica, apelidou de “caixa preta” (black box) ${ }^{29}$. A dificuldade, então, está em calibrar o desejado equilíbrio entre eficiência e transparência dos sistemas baseados em IA. Aspecto que não é apenas jurídico, mas também intrinsecamente ligado à Ciência da Computação. Ocorre que o projeto de lei não enfrentou o tema, sequer de forma superficial. Ao contrário do que fora feito em algumas iniciativas estrangeiras como, por exemplo, nas Orientações Éticas Para uma I.A. de Confiança $^{30}$, da União Europeia, a qual exige que o administrador do sistema de IA documente e monitores os processos de tomada de decisão, para identificar rapidamente eventuais falhas, bem como que seja minimamente capaz de explicar os passos que conduziram à tomada de decisão. Até mesmo a China (que notoriamente não tem uma cultura de transparência tão evoluída quanto a da Europa) se preocupou com o tema, nos Princípios para a Governança de Inteligência Artificial ${ }^{31}$, de 2019.

$\mathrm{O}$ inciso $\mathrm{V}$ traz um princípio deveras polêmico e que será mais detalhado em tópico futuro: a obrigatoriedade de supervisão humana em todo e qualquer sistema de IA. Desde já, adianta-se que esse princípio está em contrariedade ao art. 20 da LGPD que, ao tratar do direito à revisão de decisões exclusivamente automatizadas, optou por retirar essa obrigatoriedade de participação humana, internacionalmente conhecida como human in the loop ${ }^{32}$. Ou seja, pela redação atual da

Explanation' is probably not the remedy you are looking for. Duke Law \& Technology Review. Durham: Duke University School of Law. v. 16, n. 01, p. 18-84, Dec. 2017; e WACHTER, Sandra; MITTELSTADT, Brent; RUSSELL, Chris. Counterfactual Explanations without Opening the Black Box: Automated Decisions and the GDPR. Harvard Journal of Law \& Technology. Cambridge: Harvard Law School. v. 31, n. 02, p. 841-887, Spring. 2018.

29 PASQUALE, Frank. The Black Box Society: The Secret Algorithms That Control Money and Information. Cambridge: Harvard University Press, 2015.

30 UNIÃO EUROPEIA. GPAN IA. Orientações Éticas para uma IA de Confiança. 2019. Comissão Europeia. Disponível em: https://europa.eu/rapid/press-release_IP-19-1893_pt.htm. Acesso em: 07 out. 2019.

${ }^{31}$ CHINA. Ministério de Ciência e Tecnologia. Governance Principles for a New Generation of Artificial Intelligence: Develop Responsible Artificial Intelligence. 2019. Disponível em: https://www.newamerica.org/cybersecurity-initiative/digichina/blog/translation-chinese-expert-groupoffers-governance-principles-responsible-ai/. Acesso em: 07 out. 2019.

32 AMBROSE, Meg Leta. Regulating the Loop: Ironies of Automation Law. In: WeRobot 2014. 2014. Miami: Miami Law School. p. 16. "Design, maintenance and accountability will keep a human in the loop, broadly defined, but I find three other justifications for recognizing the human in the loop, even after machine 
LEONARDO NETTO PARENTONI RÔMULO SOARES VALENTINI TÁRIK CÉSAR OLIVEIRA E ALVES

LGPD, uma decisão tomada por software pode ser revisada por outro software, sem qualquer intervenção humana.

Tão ou até mais importante do que esse ponto é a necessidade de que qualquer regulação contenha previsões claras a respeito da necessidade de se prevenir e combater vieses algorítmicos (algorithmic bias) $)^{33}$, que são situações nas quais um sistema de IA toma decisões "enviesadas”, prejudicando injustificadamente determinado sujeito ou grupo. Por exemplo, quando utiliza indevidamente critérios como gênero, raça, crença religiosa ou preferências políticas. $O$ viés pode tanto ser fruto de conduta dolosa e premeditada durante o desenvolvimento do sistema quanto de uma falha no seu funcionamento ou na "alimentação" do banco de dados, sem que os desenvolvedores tivessem conhecimento disto.

Finalmente, ainda dentro dos objetivos gerais de uma regulação em matéria de IA é imprescindível considerar valores como soberania e segurança nacional, tanto no âmbito militar quanto fora dele. Por exemplo, discutir em que medida essa tecnologia poderá ser utilizada em certas atividades, como na vigilância da Amazônia e na prevenção a ataques cibernéticos, além de debater temas polêmicos como a proibição de armas letais autônomas (lethal autonomous weapons - LAW).

\subsection{Trabalho e Desenvolvimento Econômico}

Art. $3^{\circ} \mathrm{A}$ disciplina do uso da Inteligência Artificial no Brasil tem por objetivo a promoção e a harmonização da valorização do trabalho humano e do desenvolvimento econômico.

Esse artigo toca em um dos mais importantes - e polêmicos - aspectos da regulação de IA: a relação entre essa tecnologia e o trabalho humano, a qual tende a ser profundamente modificada ${ }^{34}$. Há inúmeros estudos sobre o tema, inclusive com previsões quantitativas a respeito

operation status or high levels of autonomy have been reached across a range of social settings. These justifications are integration, optimization, and interaction."

33 Vide, por exemplo: O'NEIL, Cathy. Weapons of Math Destruction. New York: Crown, 2016; GSTREIN, Oskar Josef; VAN ECK, Gerard Jan Ritsema. Mobile devices as stigmatizing security sensors: the GDPR and a future of crowdsourced 'broken windows'. International Data Privacy Law. Oxford: Oxford University Press. v. 08, n. 01, p. 69-85, Feb. 2018.

34 Por exemplo: SCHWAB, Klaus. A Quarta Revolução Industrial. Tradução: Daniel Moreira Miranda. São Paulo: Edipro, 2016. p. 114. "A quarta revolução industrial poderá robotizar a humanidade e, portanto, comprometer as nossas fontes tradicionais de significado - trabalho, comunidade, família e identidade. Ou, então, podemos usar a quarta revolução industrial para elevar a humanidade a uma nova consciência 
PANORAMA DA REGULAÇÃO DA INTELIGÊNCIA ARTIFICIAL NO BRASIL: COM ÊNFASE NO PLS N. 5.051/2019

LEONARDO NETTOO PARENTONI RÔMULO SOARES VALENTINI TÁRIK CÉSAR OLIVEIRA E ALVES

do impacto que a IA pode ter na redução de postos de trabalho. Um dos mais comentados foi realizado em 2013 e concluiu que 47\% do total de postos de trabalho nos Estados Unidos estaria em risco caso houvesse avanço indiscriminado dos sistemas baseados em inteligência artificial ${ }^{35}$. Estudo mais recente ${ }^{36}$, de 2019, aponta que não apenas os trabalhadores de menores instruções devem ser atingidos, mas qualquer grupo profissional, inclusive profissionais de qualificação técnica e elevada remuneração (white-collar workers). Esses impactos devem ser sentidos com maior intensidade, num primeiro momento, em empresas da área de tecnologia, finanças, exploração de recursos naturais e indústria. Mas outros setores não estão a salvo das mudanças.

Em sentido oposto, há também estudos apontando os possíveis benefícios aos trabalhadores decorrentes da maior utilização de sistemas de IA no ambiente laboral ${ }^{37}$. Portanto, é preciso analisar este tema com cautela e baseando-se, ao máximo, em análises científicas empíricas, antes de qualquer tomada de decisão.

No Brasil, a discussão ganha contornos particulares uma vez que a proteção do trabalhador contra a automação está prevista no art. $7^{\circ}$, XXVII e no art. 239 , § $4^{\circ}$ da Constituição Federal. Não há espaço para mencionar, aqui, as inúmeras correntes de pensamento sobre o assunto. Opta-se por destacar apenas um ponto fulcral do tema: a própria finalidade dos sistemas de IA é, em certa medida, substituir o trabalho humano por tarefas realizadas por máquinas ou softwares, a chamada automação. E se os empregos são a reunião de tarefas (as atribuições da vaga de emprego) em um ou mais seres humanos, logicamente a automação tende a reduzir vagas de emprego, ainda que outras vagas sejam paralelamente criadas, para lidar com tarefas típicas das novas tecnologias. Existe sim uma relação direta entre o uso massivo de IA e a diminuição de postos de emprego. A dificuldade aqui também reside em calibrar até que a automação é desejável para determinada sociedade, em determinada época. 0 ideal é buscar o máximo possível de ganho de eficiência com menor perda de postos de trabalho. Para isso, o foco não deve estar na proteção dos postos de trabalho em si (proteção do emprego), mas na requalificação da pessoa do trabalhador, para que ele tenha condições de competir dignamente no mercado por novas

coletiva e moral com base em um sentimento comum de destino. Cabe a todos nós garantir a ocorrência deste último cenário."

${ }^{35}$ FREY, B.C.; OSBORNE, M.A. The Future of Employment: How Susceptible Are Jobs to Computerization. Oxford Martin School Program on the Impact of Future Technology Working Paper. 2013.

${ }^{36}$ MURO, Mark; WHITON, Jacob; MAXIM, Robert. What Jobs are Affected by Al? Better-paid, better-educated workers face the most exposure. Metropolitan Policy Program at Brookings. 2019.

37 Por exemplo: COCKBURN, lain M.; HENDERSON, Rebecca; STERN, Scott. The Impact of Artificial Intelligence on Innovation. NBER Working Paper n. 24449. p. 01-40. Mar. 2018. Disponível em: https://www.nber.org/papers/w24449. Acesso em: 20 jul. 2020. 
LEONARDO NETTO PARENTONI RÔMULO SOARES VALENTINI TÁRIK CÉSAR OLIVEIRA E ALVES

oportunidades, ainda que exercendo funções diferentes das quais estava acostumado. É preciso, ainda, assegurar que haja um ritmo de criação de novos postos de trabalho ao menos próximo do número de postos extintos, para viabilizar paulatinamente a transição desses trabalhadores. Esse objetivo é realçado, por exemplo, na House Resolution n. 153, dos Estados Unidos da América ${ }^{38}$.

\title{
2.4 Supervisão Humana e Responsabilidade Civil
}

\begin{abstract}
Art. $4^{\circ}$ Os sistemas decisórios baseados em Inteligência Artificial serão, sempre, auxiliares à tomada de decisão humana.

$\S 1^{\circ} \mathrm{A}$ forma de supervisão humana exigida será compatível com o tipo, a gravidade e as implicações da decisão submetida aos sistemas de Inteligência Artificial.

$\S 2^{\circ}$ A responsabilidade civil por danos decorrentes da utilização de sistemas de Inteligência Artificial será de seu supervisor.
\end{abstract}

De todos os dispositivos do projeto de lei em exame, este é, sem dúvida, o mais polêmico e o mais criticável. 0 artigo define que todos os sistemas de inteligência artificial devem ser usados como instrumento auxiliar à tomada de decisão humana, acrescentando que terão sempre um supervisor, o qual será civilmente responsável em caso de falha no sistema.

À primeira vista, parece ser louvável que os sistemas de IA tenham um supervisor humano, a fim de atrelar eventual responsabilidade civil a uma pessoa, a qual deverá monitorar o sistema para prevenir a ocorrência dos danos, ou então ser responsabilizada em decorrência deles. Ocorre que um aprofundamento técnico na matéria revela inúmeros equívocos desse raciocínio, além de um grande distanciamento em relação ao modo como os sistemas de inteligência artificial funcionam na prática.

Primeiramente, limitar a utilização de sistemas de IA somente como auxiliares à decisão humana prejudica a inovação e vai na contramão da própria finalidade de se desenvolver alguns desses sistemas, que é justamente possibilitar que certas atividades - por exemplo as insalubres ou arriscadas - sejam realizadas por máquinas ao invés de pessoas ${ }^{39}$.

\footnotetext{
${ }^{38}$ ESTADOS UNIDOS DA AMÉRICA. House of Representatives. House Resolution 153, de 27 de fevereiro de 2019. Supporting the development of guidelines for ethical development of artificial intelligence. Disponível em: https://www.congress.gov/bill/116th-congress/house-resolution/153/text. Acesso em: 07 out. 2019. ${ }^{39}$ BALKIN, Jack M. The Three Laws of Robotics in the Age of Big Data. Yale Law School Research Paper $\mathrm{n}$. 592. p. 01-28. August 2017. p. 02-03. "Indeed, we are rapidly moving from the age of the Internet to the Algorithmic Society. We will soon look back on the digital age as the precursor to the Algorithmic Society. What do I mean by the Algorithmic Society? I mean a society organized around social and economic decision making by algorithms, robots, and Al agents; who not only make the decisions but also, in some cases, carry them out."
} 
PANORAMA DA REGULAÇÃO DA INTELIGÊNCIA ARTIFICIAL NO BRASIL: COM ÊNFASE NO PLS N. 5.051/2019

LEONARDO NETTO PARENTONI RÔMULO SOARES VALENTINI TÁRIK CÉSAR OLIVEIRA E ALVES

É preciso ter em mente que o grau de interferência dos sistemas de IA na tomada de decisão pode ser classificado em três grandes grupos: a) sistemas que trazem apenas uma informação ao ser humano, a quem competirá analisar todas as informações e decidir. Como ocorre com os assistentes vocais dos telefones celulares, quando informam ao usuário quais são os restaurantes mais próximos; b) aqueles que aconselham determinada tomada de decisão. Por exemplo, softwares da área de saúde que analisam a situação do paciente e sugerem possíveis tratamentos, cabendo ao médico a decisão final; e c) aqueles que efetivamente tomam decisões, de forma autônoma e sem a necessidade de participação humana. Por exemplo, o software dos bancos online que define (e redefine) automaticamente o limite de crédito dos clientes. Ou os carros autônomos.

Exigir supervisão humana em todos os sistemas de IA, indistintamente (como prevê o projeto de lei em comento), acaba por inviabilizar o desenvolvimento desse terceiro grupo de aplicações. Isso coloca o Brasil numa posição de inferioridade em relação a vários outros países, nos quais os três níveis são permitidos e, inclusive, incentivados dentro de certos limites. Sem contar o fato de que restrições legislativas como esta, sem prévio estudo de impacto regulatório, contrariam frontalmente o art. $4^{\circ}$ da Lei n. 13.874/2019 (“Lei da Liberdade Econômica”).

Não se pretende aqui defender a automação plena e irrestrita, de toda e qualquer tarefa. Obviamente que não. Afinal, há decisões que, pela sua importância, devem ser reservadas exclusivamente ao ser humano. Por outro lado, existem sim tarefas que podem ser automatizadas com comprovados ganhos de qualidade, segurança e eficiência. Nestes casos, o uso de sistemas de IA se justifica, desde que respeitando os direitos fundamentais.

A segunda grande crítica ao modelo proposto pelo projeto de lei é que, na prática, identificar quem seria o supervisor humano pode se mostrar difícil ou mesmo impossível. Quem deve ser considerado supervisor para fins de responsabilização civil no caso de um software desenvolvido por equipe de programadores, onde cada um deles tem função específica, mas nenhum conhece os detalhes do projeto como um todo? Se esse mesmo software for licenciado para uso de terceiros, supervisor será o desenvolvedor originário ou quem efetivamente utiliza o programa no dia a dia? Pense, ainda, em quem seria o supervisor de um assistente vocal instalado em telefone celular: o fabricante do aparelho (que desenvolveu o sistema) ou o próprio usuário, proprietário do celular (que diariamente "calibra" como esse sistema irá funcionar na prática, fornecendo seus inputs e preferências pessoais)? Se o celular do exemplo anterior for revendido, isto automaticamente altera quem é o supervisor do sistema? No caso de um carro autônomo, que sabidamente reúne milhares de componentes, provenientes de fabricantes distintos, quem é o 


\section{UDIREITO}

PANORAMA DA REGULAÇÃO DA INTELIGÊNCIA ARTIFICIAL NO BRASIL: COM ÊNFASE NO PLS N. 5.051/2019

LEONARDO NETTO PARENTONI RÔMULO SOARES VALENTINI TÁRIK CÉSAR OLIVEIRA E ALVES

supervisor? Seria o fabricante de cada componente individualmente considerado? 0 fabricante final do carro? O revendedor/distribuidor? Ou o usuário que, de novo, utiliza o veículo e o "calibra" diariamente, conforme as suas preferências pessoais? Mais complexa ainda é a situação na qual um mesmo carro autônomo é utilizado por várias pessoas diferentes, no mesmo dia, por exemplo, para transporte pessoal em aplicativos como o Uber, Lyft e Cabify. Todos esses exemplos são situações concretas que já estão ocorrendo ou podem ocorrer num futuro muito próximo.

Pensando nessas situações é que alguns autores sugerem instrumentos regulatórios inteligentes para lidar com sistemas inteligentes ${ }^{40}$. Nessa linha de raciocínio, uma das possíveis estratégias é utilizar sistemas baseados em IA para monitorar e prevenir falhas em outros sistemas da mesma natureza, sem intervenção humana. Algo que, repita-se, o modelo regulatório proposto no projeto de lei não permitiria.

Ainda que, por hipótese, seja muito simples identificar no caso concreto quem é o supervisor humano responsável pelo sistema, outro ponto ainda precisará ser enfrentado. Faz sentido responsabilizar esse supervisor por todo e qualquer dano causado pelo sistema, em qualquer contexto? Haveria aqui nova hipótese de responsabilidade objetiva pelo risco integral mesmo na ausência de previsão legislativa expressa? De um lado, pode-se argumentar que as peculiaridades da inteligência artificial fazem com que esta tecnologia, mais do que várias outras, naturalmente dê azo a riscos de grande magnitude, justificando a imposição de regime mais rigoroso de responsabilidade, a fim de compelir o ser humano a prevenir a ocorrência desses riscos ou então arcar com as suas consequências jurídicas, como a responsabilização civil (e, em casos extremos, até mesmo a responsabilização criminal).

Mas por outro lado é preciso também considerar que alguns desses riscos simplesmente não poderiam ter sido previstos, dentro do atual estado da técnica e a um custo razoável, por mais diligente que fosse o desenvolvedor. Dependendo da técnica de programação utilizada, é humanamente impossível antecipar todas as possibilidades de tomada de decisão que podem vir a ser adotadas num sistema de IA. Em sistemas mais sofisticados, com aprendizagem de máquina não supervisionada (unsupervised learning), sempre haverá o risco de decisões "por conta própria”, fora dos padrões para os quais o sistema foi programado. Algo que a literatura científica

${ }^{40}$ ETZIONI, Amitai; ETZIONI, Oren. Keeping Al legal. Vand. J. Ent. \& Tech. L., v. 19, 2016. p. 133. "These oversight programs, which this Article calls 'Al Guardians', would include Al programs to interrogate, discover, supervise, audit, and guarantee the compliance of operational Al programs.". 
PANORAMA DA REGULAÇÃO DA INTELIGÊNCIA ARTIFICIAL NO BRASIL: COM ÊNFASE NO PLS N. 5.051/2019

LEONARDO NETTO PARENTONI RÔMULO SOARES VALENTINI TÁRIK CÉSAR OLIVEIRA E ALVES

denomina de comportamento emergente (emergent behavior ${ }^{41}$. Responsabilizar o supervisor humano mesmo em caso de comportamento emergente poderia ser contraproducente, do ponto de vista econômico, porque desestimularia o lançamento de novos produtos no mercado, mesmo após vários testes, quando a margem de lucro esperada pelo desenvolvedor não fosse suficiente para cobrir as estimativas de um dano hipotético, ainda que de diminuta probabilidade. Ou então encarecer sobremaneira o preço final do produto.

Nos casos de comportamento emergente, quando não houver nexo de causalidade entre a vítima de eventual dano causado por sistema de IA e algum sujeito que deva ser responsabilizado (o "supervisor do sistema", na linguagem do projeto de lei em exame), provavelmente se estará diante de um dano não indenizável ${ }^{42}$, aspecto deveras polêmico, sobretudo quando se tratar de danos pessoais (e não simplesmente patrimoniais).

Para ilustrar o quanto o comportamento emergente é polêmico, pense-se na seguinte hipótese: um carro autônomo passou com sucesso por mais de dez mil horas de testes, tanto em ambiente controlado quanto nas ruas de determinada cidade. 0 suficiente para ser aprovado segundo os mais rigorosos padrões de segurança à época aplicáveis. Foi então colocado em circulação. Até que, determinado dia, esse carro autônomo trafegava normalmente quando, de repente, uma sacola de plástico de supermercado foi arrancada pelo vento das mãos de um comprador e passou voando na frente do carro, que a confundiu com uma criança e, ao desviar, causou um acidente. É lícito e razoável exigir que os testes houvessem antevisto situações tão específicas como essa? Justifica-se transferir esse tipo de risco ao desenvolvedor do produto? Justifica-se prolongar o período de testes quase indefinidamente, para simular até mesmo as situações mais improváveis e, por consequência, atrasar a entrada no mercado de produtos que

41 TEUBNER, Gunther. Digital Personhood? The Status of Autonomous Software Agents in Private Law. Translator: Jacob Watson. Ancilla luris. Zurich: Lagen des Rechts. p. 106-149, 2018. p. 126. "Software agents act autonomously in the legal sense, when their behavior no longer follows an exclusively stimulus reaction scheme, but when they pursue their own goals and make decisions that cannot be predicted."

42 PEREIRA, Caio Mário da Silva. Instituições de Direito Civil. 19. ed. Rio de Janeiro: Forense, 1999, v. 1. p. 420-421. "Em princípio, a responsabilidade civil pode ser definida como fez o nosso legislador de 1916: a obrigação de reparar o dano, imposta a todo aquele que, por ação ou omissão voluntária, negligência ou imprudência, violar direito ou causar prejuízo a outrem (Código Civil de 1916 art. 159) [equivalente ao art. 927 do Código Civil de 2002]. Deste conceito extraem-se os requisitos essenciais: a) em primeiro lugar, a verificação de uma conduta antijurídica, que abrange comportamento contrário a direito, seja por comissão ou por omissão, sem necessidade de indagar se houve ou não o propósito de malfazer; b) em segundo lugar, a existência de um dano, tomada a expressão no sentido de lesão a um bem jurídico, seja este de ordem material ou imaterial, de natureza patrimonial ou não-patrimonial; c) e, em terceiro lugar, o estabelecimento de um nexo de causalidade entre uma e outro, de forma a precisar-se que o dano decorre da conduta antijurídica, ou, em termos negativos, que sem a verificação do comportamento contrário a direito não teria havido o atentado ao bem jurídico." 
LEONARDO NETTO PARENTONI RÔMULO SOARES VALENTINI TÁRIK CÉSAR OLIVEIRA E ALVES

podem ser muito úteis, socialmente desejáveis e ansiosamente aguardados? A resposta a essas questões não é simples e certamente ainda não foi dada nem no projeto de lei em exame nem nas demais inciativas regulatórias até o momento apresentadas no Brasil.

Lembrando que o comportamento emergente não decorre, necessariamente, de falha de algum componente do produto, de defeito de fabricação, de negligência do fabricante ou da insuficiência de testes. É algo inerente a determinados sistemas de IA dependendo da técnica com base na qual foram construídos ou do contexto no qual são utilizados. Por exemplo, ainda que todos os componentes de um dispositivo estejam funcionamento perfeitamente, é possível que ocorram erros exclusivamente por causa da interação em tempo real de múltiplos componentes, fabricados por sujeitos diversos, como nos vários dispositivos que compõem uma "cidade inteligente". Esse tema é complexo, multidisciplinar e não foi adequadamente tratado nem no projeto de lei em exame nem nos demais projetos sobre regulação de IA apresentados até agora no Brasil.

\subsection{Diretrizes para o Poder Público}

Art. $5^{\circ}$ Constituem diretrizes para a atuação da União, dos Estados, do Distrito Federal e dos Municípios no desenvolvimento da Inteligência Artificial no Brasil: I - a promoção da educação para o desenvolvimento mental, emocional e econômico harmônico com a Inteligência Artificial;

II - a criação de políticas específicas para proteção e para qualificação dos trabalhadores;

III - a garantia da adoção gradual da Inteligência Artificial;

IV - a ação proativa na regulação das aplicações da Inteligência Artificial.

Art. $6^{\circ}$ As aplicações de Inteligência Artificial de entes do Poder Público buscarão a qualidade e a eficiência dos serviços oferecidos à população.

Os artigos $5^{\circ}$ e $6^{\circ}$ do projeto de lei arrolam as diretrizes comuns de atuação do Poder Público em todos os âmbitos federativos (União, Distrito Federal, Estados-membros e Municípios). As sugestões deste tópico são menos estruturais do que em relação ao tópico anterior. Tem-se, na verdade, ajustes pontuais de técnica-jurídica que convém observar em qualquer proposta de regulação.

Primeiro, tratar também das entidades da Administração Pública Indireta com personalidade jurídica de direito público (autarquias e fundações de direito público), em sintonia, por exemplo, com o art. 182 do Código de Processo Civil. Em segundo lugar, refletir e decidir fundamentadamente se as entidades da Administração Pública Indireta com personalidade jurídica 
PANORAMA DA REGULAÇÃO DA INTELIGÊNCIA ARTIFICIAL NO BRASIL: COM ÊNFASE NO PLS N. 5.051/2019

LEONARDO NETTO PARENTONI RÔMULO SOARES VALENTINI TÁRIK CÉSAR OLIVEIRA E ALVES

de direito privado devem ou não receber tratamento diferenciado. Por exemplo, as empresas públicas, sociedades de economia mista, consórcios com personalidade de direito privado e fundações com personalidade jurídica de direito privado.

Causa especial preocupação o inciso III do art. $5^{\circ}$, o qual prescreve que a inteligência artificial será introduzida no país de forma gradual. O fundamento deste dispositivo parece ser o princípio da precaução ${ }^{43}$. Toda precaução é bem-vinda. Porém, não a ponto de inviabilizar medidas de interesse público, ainda que eventualmente súbitas. Por exemplo, o dispositivo em exame vedaria o uso massivo de um sistema experimental de IA na área médica, ainda que tivesse maior eficácia e rapidez de resposta na identificação de casos de COVID-19 ou de outras doenças, simplesmente por não se tratar de inserção gradual no país.

Mais prudente do que definir em lei quando determinada tecnologia pode ser efetivamente empregada é fixar diretrizes mínimas para que ela, a qualquer tempo em que vier a ser inserida no país, observe padrões mínimos de segurança e confiabilidade. Havendo diretrizes claras e prévias nesse sentido, competirá à própria sociedade e aos agentes econômicos envolvidos definir o ritmo de inserção de novos sistemas de IA no Brasil. Até porque assim como essas tecnologias, também a realidade social é muito dinâmica, como no citado exemplo do COVID-19.

Diretriz deveras relevante para o Poder Público e que também não consta do projeto de lei em exame é o estímulo à indústria nacional, para que ela adquira maior competividade nesse setor. A fim de que o Brasil, algum dia, possa almejar destaque no cenário internacional de IA, ao invés de ser mero consumidor de tecnologias estrangeiras. Além de reduzir o risco de "colonialismo digital”44, como alertado pela Organização das Nações Unidas.

Outra diretriz importante e que também foi omitida no projeto de lei é a cooperação internacional. Quer porque o Brasil tem um histórico de relações pacíficas com outras nações (o que é louvável), quer porque essa cooperação favorece o interesse nacional, por exemplo, em caso de uso de sistemas de IA estrangeiros ou eventual responsabilização de agentes situados no

\footnotetext{
${ }^{43}$ LOPEZ, Teresa Ancona. Princípio da Precaução e Evolução da Responsabilidade Civil. São Paulo: Quartier Latin, 2010. p. 103. "Princípio da precaução é aquele que trata das diretrizes e valores do sistema de antecipação de riscos hipotéticos, coletivos ou individuais, que estão a ameaçar a sociedade ou seus membros com danos graves e irreversíveis e sobre os quais não há certeza científica; esse princípio exige a tomada de medidas drásticas e eficazes com o fito de antecipar o risco suposto e possível, mesmo diante da incerteza."

${ }^{44}$ WENTZEL, Marina. Como a corrida mundial pelo processamento de dados pode 'colonizar' o Brasil e outros países? BBC Brasil. 13 de outubro de 2019. Disponível em: https:// www.bbc.com/portuguese/internacional49981458. Acesso em: 17 out. 2019.
} 
PANORAMA DA REGULAÇÃO DA INTELIGÊNCIA ARTIFICIAL NO BRASIL: COM ÊNFASE NO PLS N. 5.051/2019

LEONARDO NETTOO PARENTONI RÔMULO SOARES VALENTINI TÁRIK CÉSAR OLIVEIRA E ALVES

exterior $^{45}$. Este é mais um dos pontos abordados de forma praticamente uníssona nas várias iniciativas internacionais de regulação da matéria.

Finalmente, ao tratar de diretrizes para a atuação do Poder Público é fundamental ter em mente as peculiaridades do regime jurídico-administrativo ${ }^{46}$, pois o que pode ser feito e como deve ser feito no âmbito administrativo guarda profundas diferenças em relação ao setor privado. É preciso então atentar para essas particularidades, como as regras especiais de contratação no setor público, previstas, por exemplo, nas Leis n. 8.666/1993 (Lei Geral de Licitações e Contratos), 10.520/2002 (Lei do Pregão) e 12.462/2011 (Regime Diferenciado de Contratações Públicas - RDC). Qualquer proposta de regulação da IA que traga diretrizes ao setor público deve ter o cuidado de ou compatibilizar essas diretrizes com a legislação especial supracitada ou, então, alterá-la em prol da coesão e consistência do ordenamento jurídico.

Não é admissível, por exemplo, uma decisão exclusivamente automatizada em processos administrativos relacionados a licitações e contratos, pois o sistema está todo estruturado na figura do gestor público, a quem compete tomar tais decisões - eventualmente até em caráter discricionário - bem como fundamentá-las e responder por elas. Neste contexto, os sistemas públicos de IA poderiam, no máximo, informar e aconselhar o agente público, mas nunca $O$ substituir na tomada de decisão. Aqui sim faria sentido restringir o alcance de sistemas de IA

\footnotetext{
${ }^{45}$ Sobre a responsabilização de agentes no exterior, consulte-se, por exemplo: UNIÃO EUROPEIA. European Comission - Staff Working Document. Liability for emerging digital technologies. 2018. Disponível em: https://ec.europa.eu/knowledge4policy/publication/european-commission-staff-working-documentliability-emerging-digital-technologies_en. Acesso em: 20 jul. 2020. p. 09. "International level. Other countries in the world are also analysing the liability implications of emerging digital technologies. In the US, numerous states are addressing the need for legislation of autonomous vehicles, although laws vary widely among themselves since they address licensing, use or regulation issues. Outstanding concerns include questions of responsibility and liability, as well as data protection and cybersecurity threats. In Japan, the Ministry of Economy, Trade and Industry is discussing legal issues regarding Al from the perspective of rights and responsibilities, including liability."

${ }^{46}$ MELLO, Celso Antônio Bandeira de. Curso de Direito Administrativo. 32. ed. São Paulo: Malheiros, 2015. p. 55-56. "Feitas estas considerações preliminares, importa indicar quais são, em nosso entender, as 'pedras de toque' do regime jurídico-administrativo.

Partindo do universal para o particular, diríamos que o Direito Administrativo, entroncado que está no Direito Público, reproduz, no geral, as características do regime de Direito Público, acrescidas àquelas que o especificam dentro dele.

O regime de direito público resulta da caracterização normativa de determinados interesses como pertinentes à sociedade e não aos particulares considerados em sua individuada singularidade.

Juridicamente esta caracterização consiste, no Direito Administrativo, segundo nosso modo de ver, na atribuição de uma disciplina normativa peculiar que, fundamentalmente, se delineia em função da consagração de dois princípios:
}

a) supremacia do interesse público sobre o privado;

b) indisponibilidade, pela Administração, dos interesses públicos." 


\section{UDIREITO}

PANORAMA DA REGULAÇÃO DA INTELIGÊNCIA ARTIFICIAL NO BRASIL: COM ÊNFASE NO PLS N. 5.051/2019

LEONARDO NETTO PARENTONI RÔMULO SOARES VALENTINI TÁRIK CÉSAR OLIVEIRA E ALVES

apenas aos dois primeiros graus de interferência na tomada de decisão, como já detalhado em tópico anterior.

Outro condicionante específico do Direito Administrativo é a reserva do possível ${ }^{47}$, segundo a qual o Estado tem inúmeros deveres que devem ser atendidos em prol da população, porém em certos momentos a disponibilidade orçamentária pode ser insuficiente para cumprir todos eles. Nestes casos, por meio de decisão fundamentada e documentalmente comprovada é lícito ao Estado postergar o cumprimento de alguns deveres, até que a situação orçamentária o permita, desde que isto não comprometa valores fundamentais. Portanto, a reserva do possível é mais um dos fatores específicos a ser considerado em relação a sistemas de IA voltados ao Poder Público.

Finalmente, é preciso refletir sobre a competência legislativa para disciplinar o tema. Inteligência artificial será considerada matéria de competência privativa da União, nos termos do art. 22 da Constituição Federal, tal como Direito Civil e Comercial, por exemplo? Ou seria mais adequado tratá-la como competência concorrente entre os Estados-membros, nos termos do art. 24, a fim de estimular a cooperação interna dos entes federativos? Nessa matéria, o que poderia ser considerado “interesse local” passível de regulação pelos Municípios, conforme art. 30, I? Também aqui não há uma "bala de prata", receita pronta e infalível que seja indene de críticas. É preciso refletir cuidadosamente a respeito dos prós e contras de cada alternativa e, ao final, fundamentar devidamente a adoção de alguma(s) delas.

\subsection{Período de Adaptação}

Art. $7^{\circ}$ Esta Lei entra em vigor após decorridos quarenta e cinco dias de sua publicação oficial.

É sabido que algumas leis entram em vigor imediatamente, ou seja, passam a produzir todos os seus efeitos desde a data da publicação. Enquanto outras somente passam a produzir efeitos algum tempo após a publicação, para que os destinatários, durante esse período intermediário, possam conhecer quais são as novas determinações e se adaptar a elas. Tal período

\footnotetext{
${ }^{47}$ STF, Decisão Monocrática, RE. n. ${ }^{\circ}$ 436.996/SP, j. 26.10.2005, Rel. Ministro Celso de Mello; STF, Plenário, RE. n. ${ }^{\circ} 592.581 /$ RS, j. 13.08.2015, Rel. Ministro Ricardo Lewandowski.
} 


\section{UDIREITO}

PANORAMA DA REGULAÇÃO DA INTELIGÊNCIA ARTIFICIAL NO BRASIL: COM ÊNFASE NO PLS N. 5.051/2019

LEONARDO NETTO PARENTONI RÔMULO SOARES VALENTINI TÁRIK CÉSAR OLIVEIRA E ALVES

de adaptação é tecnicamente denominado vacatio legis ${ }^{48}$. Quanto mais complexa for a lei e mais difícil adaptar-se a ela, maior deveria ser o período de vacatio legis.

No Brasil, por padrão, o vacatio legis é de 45 (quarenta e cinco) dias salvo disposição em contrário, conforme art. $1^{\circ}$ do Decreto-lei n. 4.657/1942 (Lei de Introdução às Normas do Direito Brasileiro). Logo se percebe que a previsão do PL n. 5.051/2019 é absolutamente inútil e desnecessária, pois o prazo previsto no art. $7^{\circ}$ citado acima aplicar-se-ia de qualquer maneira, mesmo se o referido artigo não existisse. A única razão que justifica inserir na lei previsão expressa de vacatio legis é para consignar período diverso dos 45 dias.

Após ponderar e definir todos os aspectos regulatórios que permeiam a inteligência artificial, será preciso ainda fixar vacatio legis razoável, para que a lei nem "pegue de surpresas" seus destinatários nem, inversamente, demore tanto tempo a entrar em vigor que sua credibilidade e finalidade regulatória sejam abaladas. Para servir de parâmetro, na tradição brasileira leis notoriamente complexas costumam ter período de adaptação entre 06 e 12 meses, sendo este último o mais comum. Teve 06 meses, por exemplo, o Código Comercial de 1850. Observaram 12 meses os atuais Códigos Penal, Civil e de Processo Civil.

Diversamente, a LGPD adotou o maior período de vacatio legis da história do país. Esta lei fora publicada em agosto de 2018, com previsão inicial de entrar em vigor em fevereiro de 2020 (18 meses de adaptação, prazo que, de início, já era muito superior à média brasileira). Posteriormente, a Medida Provisória n. 869/2018 prorrogou esse prazo para agosto de 2020 (totalizando 24 meses). Mais recentemente, o Projeto de Lei do Senado n. 1.179/2020, de autoria do Senador Antônio Anastasia, introduziu uma série de medidas para mitigar os efeitos econômicos da epidemia de COVID-19 nas relações de Direito Privado. Este projeto pretendia postergar novamente a entrada em vigor da LGPD, desta vez para $1^{\circ}$ de janeiro de 2021 , sendo que as multas e demais sanções ali previstas somente poderiam ser aplicadas a partir de $1^{\circ}$ de agosto de 2021 (totalizando o recorde nacional de 36 meses) ${ }^{49}$. Durante a tramitação legislativa, no entanto, esse projeto de lei foi convertido na Lei n. 14.010/2020, cujo art. 20 passou a tratar exclusivamente da prorrogação da entrada em vigor das sanções, para agosto de 2021, tal como na proposta

\footnotetext{
48 TRABUCCHI, Alberto. Istituzioni di Diritto Civile. 42. ed. Padova: CEDAM, 2005. p. 43. "[vacatio legis] è il periodo intermedio tra la pubblicazione e l'entrata in vigore [da una legge]."

49 Não se vislumbra antagonismo entre proteção de dados pessoais e enfrentamento da COVID-19, como sugere o referido projeto de lei, que usou tal antagonismo como fundamento para prorrogar o vacatio legis da LGPD. Ao contrário, considera-se que uma disciplina legislativa adequada sobre tratamento de dados pessoais facilitaria esse combate, trazendo maior segurança jurídica a todos os envolvidos. Esse tema, porém, não será aprofundado pois não é o objeto central do texto.
} 
LEONARDO NETTO PARENTONI RÔMULO SOARES VALENTINI TÁRIK CÉSAR OLIVEIRA E ALVES

original. Por sua vez, o dispositivo que previa a prorrogação do vacatio legis do restante da LGPD para $1^{\circ}$ de janeiro de 2021 foi suprimido. Logo na sequência, outra medida provisória passou a cuidar do tema. Desta vez, a Medida Provisória n. 959/2020 - ainda em tramitação legislativa quando concluída a redação deste texto - pretendia prorrogar o vacatio legis da LGPD até 03 de maio de 2021.

Após essa breve retrospectiva legislativa pode-se concluir com uma certeza e algumas dúvidas: a) a certeza de que o processo legislativo da LGPD foi (e está sendo) deveras tortuoso e polêmico, com o maior vacatio legis da história do Brasil, levando-se em consideração a entrada em vigor das sanções apenas em $1^{\circ}$ de agosto de 2021; e b) as dúvidas sobre quando o restante da LGPD de fato entrará em vigor, pois a Medida Provisória n. 959/2020, de importância central neste tema, ainda não foi convertida em lei e, portanto, seus efeitos ainda não se tornaram definitivos.

Prosseguindo na visão dos autores deste artigo, não existe antagonismo entre proteção de dados pessoais e enfrentamento da COVID-19, como sugeriu o Projeto de Lei do Senado $\mathrm{n}$. 1.179/2020, que usou tal antagonismo como fundamento para prorrogar o vacatio legis da LGPD. Ao contrário, considera-se que uma disciplina legislativa adequada sobre tratamento de dados pessoais facilitaria esse combate, trazendo maior segurança jurídica a todos os envolvidos. Esse tema, porém, não será aprofundado pois não é o objeto central do texto. Basta, aqui, destacar o risco decorrente de longas e sucessivas prorrogações, que é o de "desmoralizar" a própria lei, sugerindo subliminarmente aos destinatários que adaptar-se a ela não deve ser tratado como prioridade pois, em último caso, existe a possibilidade de obter novas prorrogações, se assim for mais conveniente para o interessado.

Assim, qualquer que seja o teor da nova regulação de IA no Brasil, recomenda-se observar a tradição nacional, fixando-se o vacatio legis entre 06 e 12 meses, bem como cumprir fielmente o prazo que vier a ser fixado, sem prorrogações.

\section{CONCLUSÃO}

Regular a utilização de sistemas baseados em inteligência artificial é uma questão importante e que vem sendo discutida nos mais diversos países. Nos últimos anos notava-se clara disputa entre Estados Unidos da América e China pelo protagonismo mundial nessa área. O Brasil, assim como vários outros países em desenvolvimento, nunca chegou a ter tradição na matéria. Eram poucos os investimentos - públicos e privados - em sistemas de IA, bem como não havia uma 
LEONARDO NETTO PARENTONI RÔMULO SOARES VALENTINI TÁRIK CÉSAR OLIVEIRA E ALVES

estratégia nacional consolidada a esse respeito. Porém, esse cenário mudou rapidamente no final de 2019 e início de 2020. Em apenas poucos meses, a partir de setembro de 2019, foram apresentadas no país as principais iniciativas sobre o tema, tanto pelo Poder Legislativo quanto pelo Executivo.

Este estudo descreveu e analisou essas iniciativas, com destaque para o Projeto de Lei do Senado n. 5.051/2019, que foi o pioneiro a propor um modelo de regulação da inteligência artificial no Brasil. As considerações feitas ao longo do texto não se limitam ao referido projeto, pois são de ordem geral e estruturante, sendo úteis para qualquer esforço regulatório sobre o tema. Em síntese, os dois principais problemas identificados nos marcos regulatórios estudados foram o descompasso entre o que está sendo proposto e o modo como a IA funciona na prática, bem como erros de técnica jurídica.

Apesar disso, havia na sociedade e especialmente na comunidade científica brasileira grande expectativa de que 2020 seria o ano de ouro para a regulação da IA, a fim de que ao menos um dos projetos de lei seguisse adiante, fosse aperfeiçoado e aprovado, tornando-se a primeira lei nacional sobre IA, bem como que fossem instalados no país os primeiros centros de pesquisa aplicada em inteligência artificial. Entretanto, o súbito desenrolar da epidemia do novo coronavírus (COVID-19) e sua chegada ao Brasil forçou uma total revisão das prioridades, suplantando, ao menos por ora, as discussões sobre IA. Os próximos meses certamente serão destinados a superar esse desafio. Porém, quando a ordem econômica e social estiver normalizada, é certo que os olhos se voltarão novamente à IA. E quando isto ocorrer, espera-se que o presente estudo seja lembrado como uma das contribuições relevantes, até por ter sido um dos pioneiros no Brasil a tratar do tema.

\section{REFERÊNCIAS}

ACHARYA, Ashwin; ARNOLD, Zachary. Chinese Public AI R\&D Spending: Provisional Findings. Center for Security and Emerging Technology - CSET Research. p. 01-31. Dec. 2019.

AMBROSE, Meg Leta. Regulating the Loop: Ironies of Automation Law. In: WeRobot 2014. 2014. Miami: Miami Law School.

BALKIN, Jack M. The Three Laws of Robotics in the Age of Big Data. Yale Law School Research Paper n. 592. p. 01-28. August 2017.

BOSTROM, Nick. Superintelligence: Paths, Dangers, Streategies. Oxford: Oxford University Press, 2014. 
BRASIL. Câmara dos Deputados. Projeto de Lei 21/2020. 2020. Disponível em: https: // www.camara.leg.br/proposicoesWeb/fichadetramitacao?idProposicao=2236340. Acesso em: 15 mar. 2020.

BRASIL. Câmara dos Deputados. Projeto de Lei 240/2020. 2020. Disponível em: https: / / www.camara.leg.br/proposicoesWeb/fichadetramitacao?idProposicao=2236943. Acesso em: 20 jul. 2020.

BRASIL. Ministério da Ciência, Tecnologia, Inovações e Comunicações - MCTIC. Consulta Pública: Estratégia Brasileira de Inteligência Artificial. 2019. Disponível em: http://participa.br/profile/estrategia-brasileira-de-inteligencia-artificial. Acesso em: 09 fev. 2020.

BRASIL. Ministério da Ciência, Tecnologia, Inovações e Comunicações - MCTIC. Chamada de Propostas para a Criação de Centros de Pesquisas Aplicadas em Inteligência Artificial. 2020. Disponível em:

http://www.mctic.gov.br/mctic/opencms/tecnologia/inteligencia_artificial/ChamadaPropostas CriacaoCentrosPesquisasAplicadasemInteligencia_Artificial_0.html. Acesso em: 23 fev. 2020.

BRASIL. Senado da República. Projeto de Lei 5.051/2019. 2019. Disponível em: https://www25.senado.leg.br/web/atividade/materias/-/materia/138790. Acesso em: 09 fev. 2020.

BRASIL. Senado da República. Projeto de Lei 5.691/2019. 2019. Disponível em: https://www25.senado.leg.br/web/atividade/materias/-/materia/139586. Acesso em: 09 fev. 2020.

CALO, Ryan. Artificial Intelligence Policy: A Primer and Roadmap. University of Washington Research Paper. p. 01-28. August 2017.

CATH, Corinne; et alii. Artificial Intelligence and the 'Good Society': the US, EU, and UK approach. Science and Engineering Ethics. New York: Springer. v. 23, n. 02, p. 01-24, Jan. 2017.

CHINA. Ministério de Ciência e Tecnologia. Governance Principles for a New Generation of Artificial Intelligence: Develop Responsible Artificial Intelligence. 2019. Disponível em: https://www.newamerica.org/cybersecurity-initiative/digichina/blog/translation-chineseexpert-group-offers-governance-principles-responsible-ai/. Acesso em: 07.10.2019.

COCKBURN, Iain M.; HENDERSON, Rebecca; STERN, Scott. The Impact of Artificial Intelligence on Innovation. NBER Working Paper n. 24449. p. 01-40. Mar. 2018. Disponível em: https://www.nber.org/papers/w24449. Acesso em: 20 jul. 2020.

EDWARDS, Lilian; VEALE, Michael. Slave to the Algorithm? Why a 'Right to an Explanation' is probably not the remedy you are looking for. Duke Law \& Technology Review. Durham: Duke University School of Law. v. 16, n. 01, p. 18-84, Dec. 2017. 
PANORAMA DA REGULAÇÃO DA INTELIGÊNCIA ARTIFICIAL NO BRASIL: COM ÊNFASE NO PLS N. 5.051/2019

LEONARDO NETTO PARENTONI RÔMULO SOARES VALENTINI TÁRIK CÉSAR OLIVEIRA E ALVES

ESTADOS UNIDOS DA AMÉRICA. Relatório do Comitê de Tecnologia do Conselho Nacional de Ciência e Tecnologia para o Escritório Executivo do Presidente. Preparing for the Future of Artificial Intelligence, October $12^{\text {th }}$ 2016. 2016. Disponível em: https://www.whitehouse.gov/sites/default/files/whitehouse_files/microsites/ostp/NSTC/prepa ring_for_the_future_of_ai.pdf. Acesso em: 24 abr. 2018.

ESTADOS UNIDOS DA AMÉRICA. House of Representatives. House Resolution 153, de 27 de fevereiro de 2019. Supporting the development of guidelines for ethical development of artificial intelligence. Disponível em https://www.congress.gov/bill/116th-congress/houseresolution/153/text. Acesso em: 07 out. 2019.

ESTADOS UNIDOS DA AMÉRICA. Congresso. House Resolution 2231 de 10 de abril de 2019. Disponível em: https://www.congress.gov/bill/116th-congress/house-bill/2231?s=1\&r=91. Acesso em: 07 out. 2019.

Estados Unidos da América. Congresso. House Resolution.2486 de 05 de fevereiro de 2019. Disponível em: https://www.congress.gov/bill/116th-congress/house-bill/2486/text. Acesso em: 07 out. de 2019.

ESTADOS UNIDOS DA AMÉRICA. Congresso Nacional. House Resolution 3388 de 09 de julho de 2017. 2017. Disponível em: https://www.congress.gov/bill/115th-congress/house-bill/3388. Acesso em: 07 out. 2019.

ETZIONI, Amitai; ETZIONI, Oren. Keeping Al legal. Vand. J. Ent. \& Tech. L., v. 19, 2016.

FREY, B.C.; OSBORNE, M.A. The Future of Employment: How Susceptible Are Jobs to Computerization. Oxford Martin School Program on the Impact of Future Technology Working Paper. 2013.

GSTREIN, Oskar Josef; VAN ECK, Gerard Jan Ritsema. Mobile devices as stigmatizing security sensors: the GDPR and a future of crowdsourced 'broken windows'. International Data Privacy Law. Oxford: Oxford University Press. v. 08, n. 01, p. 69-85, Feb. 2018.

KAPLAN, Jerry. Artificial Intelligence: What everyone needs to know. Oxford: Oxford University Press, 2016.

KURZWEIL, Ray. The Singularity Is Near: When Humans Transcend Biology. New York: Penguin Group, 2005.

LOPEZ, Teresa Ancona. Princípio da Precaução e Evolução da Responsabilidade Civil. São Paulo: Quartier Latin, 2010.

MAGRANI, Eduardo; OLIVEIRA, Renan Medeiros de. A internet das coisas e a Lei Geral de Proteção de Dados: reflexões sobre os desafios do consentimento e do direito à explicação. Revista do Advogado. São Paulo: AASP, Ano XXXIX, n. 144, p. 80-89, nov. 2019.

MAYER-SCHÖNBERGER, Viktor; CUKIER, Kenneth. Big Data. 2. ed. Boston/New York: Eamon Dolan/Houghton Mifflin Harcourt, 2014. 


\section{UDIREITO}

PANORAMA DA REGULAÇÃO DA INTELIGÊNCIA ARTIFICIAL NO BRASIL: COM ÊNFASE NO PLS N. 5.051/2019

LEONARDO NETTO PARENTONI RÔMULO SOARES VALENTINI TÁRIK CÉSAR OLIVEIRA E ALVES

MELLO, Celso Antônio Bandeira de. Curso de Direito Administrativo. 32. ed. São Paulo: Malheiros, 2015.

MURO, Mark; WHITON, Jacob; MAXIM, Robert. What Jobs are Affected by AI? Better-paid, bettereducated workers face the most exposure. Metropolitan Policy Program at Brookings. 2019.

NILSSON, Nils J. The Quest for Artificial Intelligence: A History of Ideas and Achievements. Cambridge: Cambridge University Press, 2010.

O'NEIL, Cathy. Weapons of Math Destruction. New York: Crown, 2016.

PASQUALE, Frank. The Black Box Society: The Secret Algorithms That Control Money and Information. Cambridge: Harvard University Press, 2015.

PEREIRA, Caio Mário da Silva. Instituições de Direito Civil. 19. ed. Rio de Janeiro: Forense, 1999, v. 1.

RUSSELL, Stuart J.; NORVIG, Peter. Artificial Intelligence: A Modern Approach. 3. ed. New Jersey: Prentice-Hall, 2010.

SCHWAB, Klaus. A Quarta Revolução Industrial. Tradução: Daniel Moreira Miranda. São Paulo: Edipro, 2016.

TEUBNER, Gunther. Digital Personhood? The Status of Autonomous Software Agents in Private Law. Translator: Jacob Watson. Ancilla luris. Zurich: Lagen des Rechts. p. 106-149, 2018.

THEODORO JÚNIOR, Humberto. O Contrato e sua Função Social. 2. ed. Rio de Janeiro: Forense, 2004.

TRABUCCHI, Alberto. Istituzioni di Diritto Civile. 42. ed. Padova: CEDAM, 2005.

UNIÃO EUROPEIA. European Comission - Staff Working Document. Liability for emerging digital technologies. 2018. Disponível em:

https://ec.europa.eu/knowledge4policy/publication/european-commission-staff-workingdocument-liability-emerging-digital-technologies_en. Acesso em: 20 jul. 2020.

UNIÃO EUROPEIA. GPAN IA. Orientações Éticas para uma IA de Confiança. 2019. Comissão Europeia. Disponível em: https://europa.eu/rapid/press-release_IP-19-1893_pt.htm. Acesso em: 07 out. 2019.

WACHTER, Sandra; MITTELSTADT, Brent; RUSSELL, Chris. Counterfactual Explanations without Opening the Black Box: Automated Decisions and the GDPR. Harvard Journal of Law \& Technology. Cambridge: Harvard Law School. v. 31, n. 02, p. 841-887, Spring. 2018.

WENTZEL, Marina. Como a corrida mundial pelo processamento de dados pode 'colonizar' o Brasil e outros países? BBC Brasil. 13 de outubro de 2019. Disponível em:

https://www.bbc.com/portuguese/internacional-49981458. Acesso em: 17 out. 2019. 


\section{COMO FAZER REFERÊNCIA AO ARTIGO (ABNT):}

PARENTONI, Leonardo Netto; VALENTINI, Rômulo Soares; ALVES, Tárik César Oliveira e. Panorama da regulação da inteligência artificial no Brasil: com ênfase no PLS N. 5.051/2019. Revista Eletrônica do Curso de Direito da UFSM, Santa Maria, RS, v. 15, n. 2, e43730, mai./ago. 2020. ISSN 1981-3694. DOI: http://dx.doi.org/10.5902/1981369443730. Disponível em:

https://periodicos.ufsm.br/revistadireito/article/view/43730. Acesso em: dia mês. ano.

Direitos autorais 2020 Revista Eletrônica do Curso de Direito da UFSM

Editores responsáveis: Rafael Santos de Oliveira e Angela Araujo da Silveira Espindola

\section{cc) $\$(9)$}

Esta obra está licenciada com uma Licença Creative Commons Atribuição-NãoComercial-SemDerivações 4.0 Internacional.

\section{SOBRE OS AUTORES}

\section{LEONARDO NETTO PARENTONI}

Doutor em Direito pela USP. Mestre em Direito Empresarial pela UFMG. Especialista em Direito Processual Civil pela UnB. Procurador Federal de Categoria Especial/AGU. Professor Adjunto de Direito Empresarial da UFMG e Titular do IBMEC/MG. Fundador e Conselheiro Científico do Centro de Pesquisa em Direito, Tecnologia e Inovação - DTIBR (www.dtibr.com). Fundador e Coordenador da área de concentração em Direito, Tecnologia e Inovação na Pós-Graduação da Faculdade de Direito da UFMG. Ex-membro de Comissões do Conselho Nacional de Justiça, do Conselho da Justiça Federal, da Procuradoria-Geral Federal e da $\mathrm{OAB} / \mathrm{MG}$. Pesquisador Visitante na Universidade do Texas em Austin/USA e na Agência de Proteção de Dados do Uruguai. Parceiro tecnológico estratégico (Programa KTP) na Universidade de Tecnologia de Sydney. Mentor de Equipe no Programa Law Without Walls - LWOW/USA. Principais áreas de atuação: 1) Direito, Tecnologia e Inovação; 2) Direito Societário; 3) Análise Empírica do Direito (Empirical Legal Studies - ELS). Número de Identificação como Pesquisador Internacional (Researcher ID): N-5627-2015.

\section{RÔMULO SOARES VALENTINI}

Doutor em Direito pela Universidade Federal de Minas Gerais. Mestre em Direito pela Universidade Federal de Minas Gerais. Especialista em Direito Material e Processual do Trabalho. Bacharel em Direito. Professor convidado do programa de pósgraduação da UFMG na linha de pesquisa Estado, Razão e História, na disciplina Temas de Direito do Trabalho Comparado: 0 Futuro do Trabalho. Professor de Direito do Trabalho na FPL/MG. Analista Judiciário da $45^{a}$ Vara do Trabalho de Belo Horizonte, Tribunal Regional do Trabalho da $3^{\text {a }}$ Região.

\section{TÁRIK CÉSAR OLIVEIRA E ALVES}

Graduando em Direito pela Universidade Federal de Minas Gerais. É cofundador e membro organizador/pesquisador do Centro DTIBR e membro do grupo de pesquisa GPDE da UFMG. 